\title{
Carbon Electrodes Electrolysis Process in Removing COD, Turbidity and Color for Textile Wastewater
}

ISSN: 2639-0574

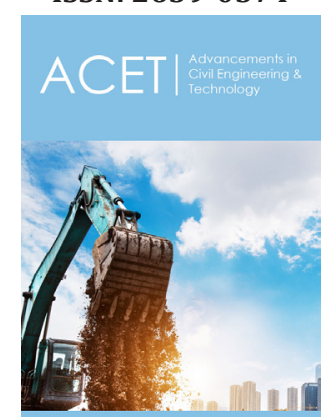

*Corresponding author: Yusoff MS, School of Civil Engineering, Universiti Sains Malaysia suffian@usm.my

Submission: 梅 September 08, 2020

Published: 海October 09, 2020

Volume 4 - Issue 3

How to cite this article: Yusoff MS, Shahirah Basenun NF, MohdYusoff $\mathrm{NH}_{,}$ Abdul AzizH, Alazaiza MYD. Carbon Electrodes Electrolysis Process in Removing COD, Turbidity and Color for Textile Wastewater. Adv Civil Eng Tech. 4(3). ACET.000590. 2020.

DOI: 10.31031/ACET.2020.04.000590

Copyright@ Yusoff MS, This article is distributed under the terms of the Creative Commons Attribution 4.0 International License, which permits unrestricted use and redistribution provided that the original author and source are credited.

\author{
Yusoff MS ${ }^{1,2 *}$, Basenun NFS ${ }^{1}$, Yusoff $\mathrm{NHM}^{1}$, Aziz HA ${ }^{1,2}$ and Alazaiza MYD ${ }^{3}$ \\ ${ }^{1}$ School of Civil Engineering, Universiti Sains Malaysia, Pulau Pinang, Malaysia \\ ${ }^{2}$ Solid Waste Management Cluster, Science and Technology Research Centre, Universiti Sains \\ Malaysia, Pulau Pinang, Malaysia \\ ${ }^{3}$ Department of Civil and Environmental Engineering, College of Engineering (COE), \\ A'Sharqiyah University (ASU), Oman
}

\begin{abstract}
This paper investigates the removal efficiency of textile wastewater using electrolysis process by carbon electrodes. The performance of COD, turbidity, and color reductions was evaluated under different conditions of $\mathrm{pH}$, voltage usage, and distance between electrodes. The optimum conditions were determined, and the size of the flocs using these conditions was determined. Results showed that maximum COD, turbidity and color reduction were achieved under optimum pH6 conditions, constant $9 \mathrm{~V}$ voltage, and $1 \mathrm{~cm}$ distance between the electrodes with an average of $85.5 \%, 89.2 \%$, and $85.2 \%$ respectively. It was found that higher voltage value, shorter distance between electrodes and neutral $\mathrm{pH}$ resulted in higher removal efficiency. The flocs size was found to be higher in the case of the short distance between electrodes. Overall, this study demonstrates that the electrolysis process is an effective method of treating textile wastewater and relatively rapid compared to other conventional techniques.
\end{abstract}

Keywords: Textile wastewater;Electrolysis;Carbon electrode;Flocs size

\section{Introduction}

Textile factories generally use high volumes of water and various chemicals for finishing and coloring processes. Wastewater produced from the dyeing process consists of a variety of pollutants, which includes acids, bases, suspended and dissolved solids, toxic and nonbiodegradable compounds, which are detected even at low levels and must be treated before the wastewater is released into the environment [1,2]. More than 100,000 commercially available textile colors are estimated to be registered and presented in the industry, where it generates about 700,000-1,000,000 tons of dyes, and approximately 280,000 tons were released annually into the global environment through textile industry effluents [3]. Dyeing and finishing processes are two subsequent stages in the textile manufacturing process. These stages include man-made or natural fibres being tinted to the required permanent color and processed into final commercial items [4]. Dyes can potentially have a harmful effect on human health and can be carcinogenic [5]. The existence of dyes in wastewater, even at low concentrations, is not acceptable as they can lead to esthetic and hazardous impacts on the environment when they are disposed of. In general, textile wastewater encompasses strong colors, high pH fluctuation, and high concentration of COD and suspended solids (SS) [6]. The process of treating this textile wastewater is therefore very difficult because of these properties.

During the last few decades, several researchers have applied different treatment techniques for textile wastewater [7-11]. The selection of a proper treatment technique usually depends on the textile plant's manufacturing process and chemicals, effluent constituents, discharge requirements, reuse/recycling options and the skills and expertise available. In some textile mills, the effluent produced from various processes can be distinguished as concentrated (paddler-tinting/finishing fillings, printing and dye-baths), medium polluted 
(washing and rinsing) and low/zero polluted wastewater [12]. This effluent separation assists in the selection of efficient treatment methods. However, in most cases, effluents produced from different processes are discharged from the final outlet together as composite wastewater [13].

Textile wastewater treatment processes can be divided into three known processes: separation and concentration processes, processes of decomposition and degradation, and process of exchange [14]. Usually, a proper combination of these processes is applied in full-scale treatment systems to meet the final discharge according to water treatment standards. Anaerobic biodegradation (as a pretreatment technique) is generally integrated into the treatment of textile wastewater that has high- resistance effluents [9]. However, anaerobic systems are costly. Several researchers have previously used other methods of treatment for textile wastewater, such as electrochemical [15,16], adsorption [17], advanced oxidation [18] and coagulation [19]. Coagulation-flocculation technique is a cheap and cost-effective method, easy to operate, and does not requires high energy. However, the efficiency of the coagulation process is not high for soluble dyes [19]. In addition, the coagulation process generates a high amount of sludge which can adversely affect the treatment process and increase the cost of treatment [20].

The electrolysis process is widely used for treating wastewater. The method depends on the generation of coagulants in the wastewater through the electrodes, usually made of metals like aluminum or iron. The electrodes release ions which neutralize particle charges and thus initiate coagulation. These ions are able to remove contaminants by merging materials and by electro-flotation [21]. The main processes were electrolytic reactions on the surface of the electrode, followed by the formation of coagulants in an aqueous phase, the adsorption of soluble or colloidal pollutants and the removal of pollutants by sedimentation and flotation. The destabilized particles then combine to form flocs, while tiny cathode-formed hydrogen bubbles induce the majority of flocs to help isolate wastewater particles effectively [21].

The main aim of this study is to investigate the effectiveness of color, turbidity and COD removal from textile wastewater using the electrolysis process. Specifically, two electrodes made of carbon were used as electrodes. Different conditions of $\mathrm{pH}$, voltage usage, and distances between electrodes were applied to investigate the optimum conditions that resulted in the maximum removal efficiency. In addition, the size of the flocs was investigated using the optimum conditions determined from experiments.

\section{Materials and Methods}

\section{Textile wastewater collection and sampling}

Samples of textile wastewater were collected from the Craft Batik Teluk Bahang factory located at Pulau Pinang, Malaysia, in February 2019. The samples were taken directly from a pipe located after dying and washing process using 20L high-density polyethylene bottles to prevent the contamination of samples. The wastewater from the textile process started after dying and washing process in the industry. Normally, in Batik industry, different types of dyes in batik processing were used such as azo dye. Effluents from textile mills were characterized by a high color concentration due to residual dyes. The collected samples were transported to the laboratory within 1 hour and kept in a cold room at $4{ }^{\circ} \mathrm{C}$ to avoid possible chemical and biological reactions before starting the experiments. The samples were acclimatized for 2-3 hours at room temperature before each experiment began. The major parameters tested were $\mathrm{pH}$, turbidity, COD, and color and analysed according to the Standard Method of Water and Wastewater. The main parameters tested were $\mathrm{pH}$, turbidity, COD and color and analysed by the American Public Health Association [22]. The temperature and $\mathrm{pH}$ were determined by YSI Professional Plus Quatro, Eutech pH700. Turbidity was determined using a turbidity meter (HACH $2100 \mathrm{~N}$ ). Measurement of COD and colour was done by $\mathrm{HACH}$ DR2800 spectrophotometer.

\section{Experimental setup}

The treatment of textile effluent using electrolysis process was carried out using different components such as reactor, a pair of electrodes, electrode clamps, direct current (DC) power supply, magnetic stirrer, and magnetic bar. A $500 \mathrm{~mL}$ glass beaker was used as an electrolytic cell where $300 \mathrm{~mL}$ of textile sample was used for the test. Two electrodes made of carbon were used in this study. This type of electrode was employed for both cathode and anode electrodes. Carbon was chosen due to cheaper cost and easier to obtain. The electrodes were placed in a glass beaker known as an electrolytic cell. The two electrodes were set up in a vertical position with different distances of $1 \mathrm{~cm}, 2 \mathrm{~cm}, 3 \mathrm{~cm}$ and $4 \mathrm{~cm}$ between the cathode and the anode. The electrodes were attached with an electrode clamp in order to ensure that the electrode is in a fixed position when immersed in a textile wastewater sample. The various distances between the electrodes are one of the variables that investigated in this study. Both electrodes were connected to a DC power supply, which supplies electrical current through the electrolysis process. A magnetic stirrer and magnetic bar were also used to enhance pollutant removal [23]. The experiments were performed with different voltages of $3 \mathrm{~V}, 6 \mathrm{~V}$, and $9 \mathrm{~V}$. In addition, different $\mathrm{pH}$ ranges were used in the experiments varied from $\mathrm{pH} 4$, pH6, and pH8. All experiments were carried with four different inter distance between electrodes of $1 \mathrm{~cm}, 2 \mathrm{~cm}, 3 \mathrm{~cm}$, and $4 \mathrm{~cm}$. Three main factors were considered during the experiments like the influence of voltages, the effect of $\mathrm{pH}$, and the impact of distance of inter electrodes. All textile samples were tested for COD, color, and turbidity.

\section{Determination of floc size}

Destabilized particles in textile wastewater will aggregate into flocs. Also, cathode will generate tiny hydrogen bubbles and induce the flotation of the majority of flocs, where only a small percentage of the flocs will sink to the bottom. These flocs formed will help 
to effectively separate particles from wastewater. The size of flocs formed is one of the floc properties; thus, it is significant to measure the size of flocs to know the influence of the size of the flocs on the effectiveness of removal pollutant. In this study, the size of the flocs was measured using the Malvern Mastersizer 2000 particle size analyzer.

\section{Results and Discussion}

\section{Characteristics of textile wastewater}

The detailed features of the wastewater samples are summarized in Table 1. The raw textile wastewater has a dark-purple color (645Pt Co) with an average $\mathrm{pH}$ of 10.98 . The acceptable range of color is $200 \mathrm{Pt}$ Co. The high $\mathrm{pH}$ value indicates that the textile wastewater was alkaline. The acceptable range of $\mathrm{pH}$ is between 5.5 and 9 (MQA, 2009). Having high alkalinity is intolerable as it is an indication that the textile wastewaters have the capacity to neutralize acids [24]. On the other hand, color is often caused by forms of organic matter content that cause color pollution induces synthetic chemical dyes and natural dissolved organics such as lignin and tannins [25]. The color and $\mathrm{pH}$ exceeded the acceptable conditions for the discharge of industrial wastewater effluent [26]. The COD value was $460 \mathrm{mg} / \mathrm{L}$, which is also unacceptable to discharge without treatment (acceptable range for COD is 80$250 \mathrm{mg} / \mathrm{L}$ ). Turbidity value was 24.22 NTU which is also higher than the acceptable range for a discharge without treatment.

Table 1: Textile wastewater characteristics.

\begin{tabular}{|c|c|c|}
\hline Parameters & Value & Standard* \\
\hline $\mathrm{pH}$ & 10.98 & $5.5-9.0$ \\
\hline COD (mg/L) & 460 & 250 \\
\hline Turbidity (NTU) & 24.22 & - \\
\hline Colour (Pt Co) & 645 & 200 \\
\hline
\end{tabular}

* Adapted from Environmental Quality (Industrial Effluents) Regulation 2009

\section{Color removal}

As stated, different $\mathrm{pH}$ was used to determine the optimum $\mathrm{pH}$ of the treatment. Figure 1 portrays the removal efficiency of color using different $\mathrm{pH}$, different voltages, and different distances between electrodes. Using raw $\mathrm{pH}$ of textile wastewater (10.25) and $9 \mathrm{~V}$, the removal efficiency of color at distance of inter-electrode of $1 \mathrm{~cm}, 2 \mathrm{~cm}, 3 \mathrm{~cm}$ and $4 \mathrm{~cm}$ was $43.9 \%$ (562 to $315 \mathrm{PtCo}$ ), $26.3 \%$ (562 to $414 \mathrm{PtCo}$ ), $25 \%$ (415 to $313 \mathrm{PtCo}$ ) and $23 \%$ (418 to $319 \mathrm{PtCo}$ ), respectively (Figure 1). It can be noted that the maximum removal of color was obtained at $1 \mathrm{~cm}$ of a distance of inter-electrode (43.9\%), whereas the lowest removal of color was obtained at $4 \mathrm{~cm}$ distance of inter-electrode (23\%). When the voltage was changed to $6 \mathrm{~V}$, the reduction of color was $25.3 \%, 23 \%, 21 \%$, and $18 \%$ at a distance of inter-electrode of $1 \mathrm{~cm}, 2 \mathrm{~cm}, 3 \mathrm{~cm}$ and $4 \mathrm{~cm}$, respectively. When the voltage value was decreased to $3 \mathrm{~V}$, the removal efficiency of color was $29 \%, 28 \%, 25 \%$ and $23 \%$ at the different distance of inter-electrodes. In conclusion, the highest color reduction was achieved using $9 \mathrm{~V}$ at an inter-electrode distance of $1 \mathrm{~cm}$ with $43.9 \%$ (562 to 398PtCo).

At pH4 of electrolysis (Figure 1) and using a voltage value of $9 \mathrm{~V}$, the percentage removal of color was $63 \%$ (463 to 169PtCo), $52 \%$ (463 to $220 \mathrm{PtCo}$ ), 39\% (305 to 186PtCo), and 35\% (315 to $203 \mathrm{PtCo}$ ) at the different distance of inter-electrodes. When the constant voltage decreased to $6 \mathrm{~V}$, the color reduction was $30.1 \%$, $29 \%, 28 \%$ and $26 \%$. When the constant voltage was decreased again to $3 \mathrm{~V}$, the percentage removal of color was $27.8 \%, 21 \%$, $19 \%$ and $13 \%$ at a distance of inter-electrode of $1 \mathrm{~cm}, 2 \mathrm{~cm}, 3 \mathrm{~cm}$ and $4 \mathrm{~cm}$ respectively. According to Manikandan et al. [27], the color removal at pH4 was $69.31 \%$ which is slightly higher than the maximum color removal obtained from the current study $(63 \%)$ at $1 \mathrm{~cm}$ distance of inter-electrode and 9V. In general, by using low $\mathrm{pH}$, a higher volume of hydrogen is produced by electro-reduction in the cathode; therefore, less proportion of hydroxide ions can result. By comparing the results of $\mathrm{pH} 6$, the acidic condition resulted in the least efficiency than neutral condition. This is because, during the electrolysis process, the dominant carbon species will act as a coagulating agent. At $\mathrm{pH} 4$, the removal efficiency was lower because of the formation of soluble carbon complexes [28].

At $\mathrm{pH} 6$ (Figure 1) and using constant voltage of 9V, the percentage removal of color was $85.2 \%$ (687 to $102 \mathrm{PtCo}$ ), $81 \%$ (468 to $82 \mathrm{PtCo}$ ), 69\% (353 to 109PtCo), and 65\% (350 to $122 \mathrm{PtCo}$ ) at the different distance of inter-electrodes. When the constant voltage was decreased to $6 \mathrm{~V}$, the removal efficiency of color was decreased to $63.4 \%, 61 \%, 54 \%$, and $50 \%$ using the previous distances between electrodes, respectively. With more decreasing of constant voltage to $3 \mathrm{~V}$, the removal efficiency was decreased to $52.3 \%, 51 \%, 46 \%$, and $41 \%$ at the same distances between electrodes. According to Naje et al. [29], the color removal using pH6 and distance of inter-electrode $1 \mathrm{~cm}$ was $94 \%$ which is slightly higher than the result obtained from the current study (85.2\%). Chen [30] stated that higher voltages lead to higher removal.

When the $\mathrm{pH}$ of the electrolysis was increased to 8 (Figure 1), and a constant voltage of $9 \mathrm{~V}$, the removal efficiency of color was $69.8 \%$ (891 to $269 \mathrm{PtCo}$ ), $43 \%$ (497 to $280 \mathrm{PtCo}$ ), 36\% (390 to $249 \mathrm{PtCo}$ ), and $32 \%$ (388 to 265PtCo) at the same distances between electrodes. However, when the value of voltage was decreased to $6 \mathrm{~V}$, the removal efficiency of color decreased to $30.2 \%, 29 \%$, $27 \%$ and $23 \%$ at the same distances between electrodes. Further reduction in voltage to $3 \mathrm{~V}$ resulted in a reduction of color removal efficiency to $26.3 \%, 24 \%, 21 \%$ and $18 \%$ at the same distances between electrodes. Overall, it can be summarized that maximum color reduction was achieved at $\mathrm{pH} 6,9 \mathrm{~V}$ constant voltage and $1 \mathrm{~cm}$ distance between the electrodes. 

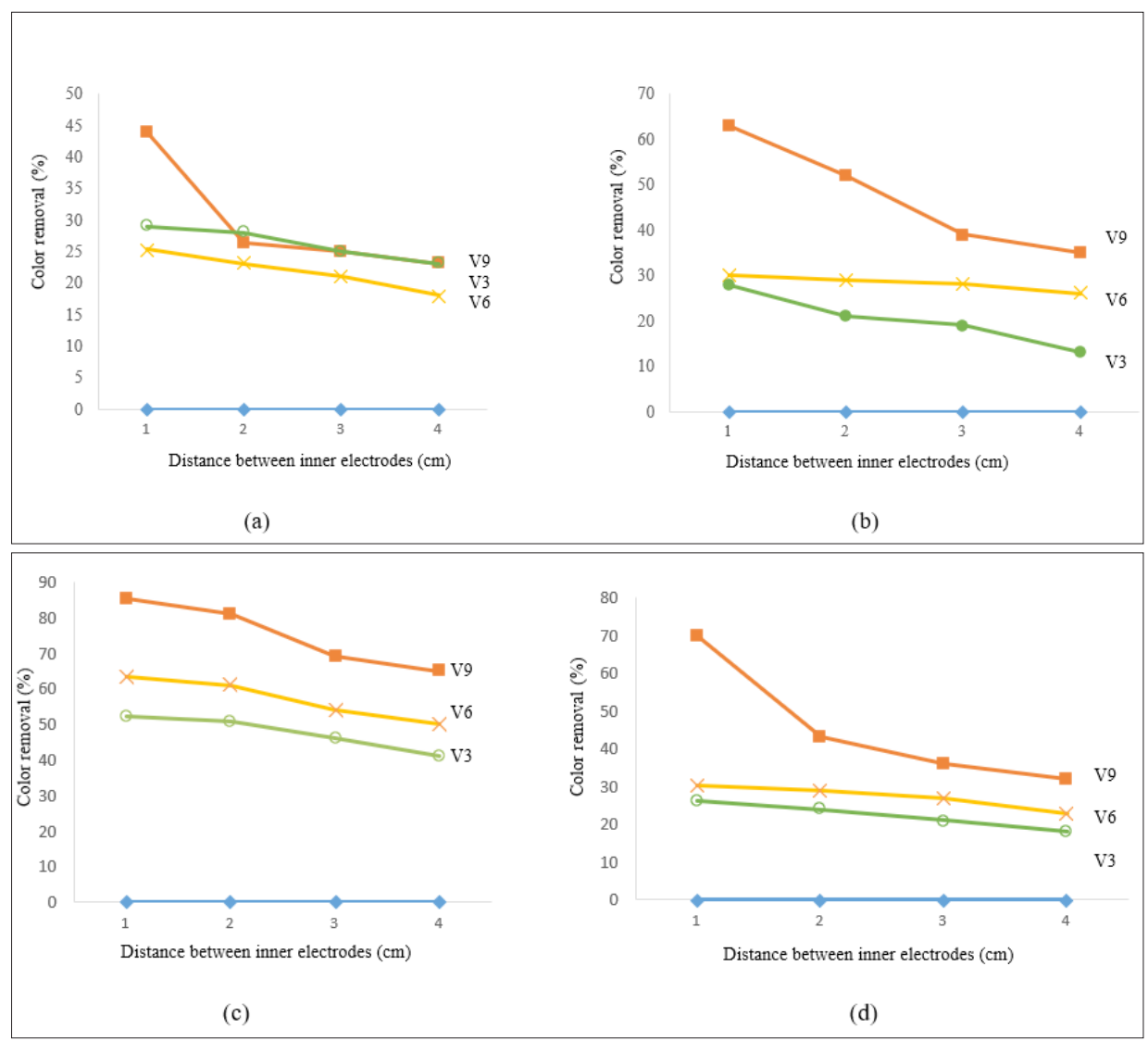

Figure 1: Effect Removal efficiency of color versus distance between inner electrodes at (a) raw $\mathrm{pH}$, (b) $\mathrm{pH} 4$, (c) $\mathrm{pH}$, and (d) $\mathrm{pH} 8$

\section{Turbidity removal}

Similarly, the turbidity removal of textile wastewater was evaluated using different $\mathrm{pH}$ values, constant voltage values, and distances between electrodes as shown in Figure 2. Using raw $\mathrm{pH}$ of electrolysis (Figure 2) and voltage value of $9 \mathrm{~V}$, the removal efficiency of turbidity was $52.3 \%$ (24.44 to $11.65 \mathrm{NTU}$ ), $37 \%$ (21.07 to $13.28 \mathrm{NTU}$ ), $34 \%$ ( 22.8 to $15.4 \mathrm{NTU}$ ), and $26 \%$ (22.1 to $16.3 \mathrm{NTU}$ ) at distances between electrodes of $1 \mathrm{~cm}, 2 \mathrm{~cm}, 3 \mathrm{~cm}$ and $4 \mathrm{~cm}$, respectively. In contrast to color removal, when the voltage value decreased to $6 \mathrm{~V}$, the removal efficiency of turbidity was increased to $58 \%, 40 \%, 37 \%$, and $35 \%$ at the same distances as mentioned earlier. Further decrease of voltage value to $3 \mathrm{~V}$ leads to higher removal efficiency of turbidity using the same distances between electrodes except for the case of $1 \mathrm{~cm}$ distance between electrodes. The percentage removal of turbidity was $49.6 \%, 46 \%, 43 \%$, and $40 \%$.

When the $\mathrm{pH}$ was increased to 4 (Figure 2), and a voltage value of $9 \mathrm{~V}$, the percentage removal of turbidity was $62.6 \%(7.84$ to $2.93 \mathrm{NTU}$ ), $48 \%$ (23.83 to $12.26 \mathrm{NTU}$ ), $47 \%$ (33.46 to $17.5 \mathrm{NTU}$ ), and $44 \%$ (32.8 to $18.3 \mathrm{NTU}$ ) using the different distances between the electrodes. When the voltage value was decreased to $6 \mathrm{~V}$, further decrease in turbidity was noted and reached to $49.1 \%, 39 \%, 37 \%$ and $32 \%$. Further decrease in the voltage value to $3 \mathrm{~V}$ resulted in lower removal efficiency of turbidity of $40.5 \%, 39 \%, 23 \%$ and $17 \%$ at the different distances between electrodes.

When the $\mathrm{pH}$ was increased to 6 (Figure 2), and a voltage value of $9 \mathrm{~V}$, the percentage removal of turbidity was $89.2 \%$ (10.08 to $1.08 \mathrm{NTU}$ ), $75 \%$ (35.88 to $8.96 \mathrm{NTU}$ ), $64 \%$ (20.92 to $7.55 \mathrm{NTU}$ ), and $57 \%$ (22.6 to $9.63 \mathrm{NTU}$ ) at the different distances between electrodes. The removal efficiency of the turbidity at pH6 is obviously higher than that of the raw $\mathrm{pH}$ and $\mathrm{pH}$ of 4 . According to Zarei et al. [31], the acidic condition will result in slightly lower removal of turbidity than neutral condition. This finding is due to the formation of small flocs that impact the coagulation and sedimentation process and reduce its effectiveness. When the voltage values decreased to $6 \mathrm{~V}$ and $3 \mathrm{~V}$, the removal efficiency of turbidity was decreased to $74.3 \%, 70 \%, 65 \%, 47 \%$ and $54.7 \%$, $52 \%, 48 \%$ and $36 \%$ respectively.

At pH 8 (Figure 2) and using voltage values of 9V, the percentage removal efficiency of turbidity was $82.8 \%$ (12.15 to $2.08 \mathrm{NTU}$ ), $65 \%$ (32.51 to $11.5 \mathrm{NTU}$ ), $49 \%$ (32.48 to $16.64 \mathrm{NTU}$ ), and $47 \%$ (30.5 to $16.1 \mathrm{NTU}$ ). Further decrease of voltage value to $6 \mathrm{~V}$ and $3 \mathrm{~V}$ resulted in lower removal efficiency of turbidity to $20 \%, 18 \%$, $12 \%, 11 \%$ and $41.8 \%, 40 \%, 36 \%$, and $27 \%$, respectively. It can be summarized that at optimum conditions $\mathrm{pH} 6,9 \mathrm{~V}$ voltage value and $1 \mathrm{~cm}$ distance between electrodes, the highest removal efficiency of turbidity was achieved. 


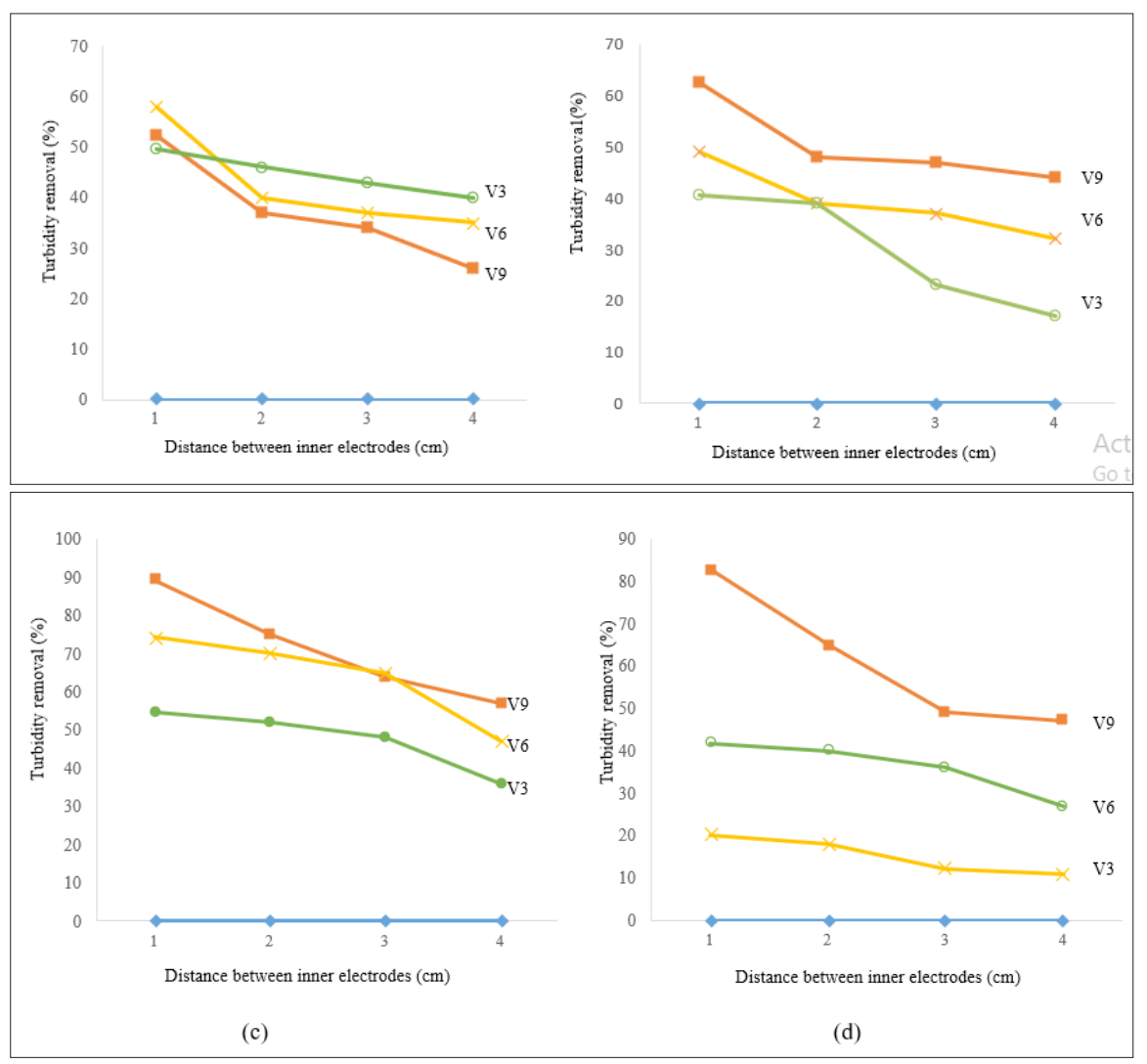

Figure 2: Removal efficiency of turbidity versus distance between inner electrodes at (a) raw $\mathrm{pH}$, (b) $\mathrm{pH} 4$, (c) pH6 and (d) $\mathrm{pH} 8$

\section{COD removal}

COD removal was also observed under different conditions of $\mathrm{pH}$, voltage value, and distances between electrodes, as shown in Figure 3. At raw $\mathrm{pH}$ (Figure 3) and using $9 \mathrm{~V}$ as a constant voltage, the removal efficiency of COD was $37.2 \%$ (456 to $286 \mathrm{mg} / \mathrm{L}$ ), $30 \%$ (415 to $290 \mathrm{mg} / \mathrm{L}$ ), 29\% (412 to $293 \mathrm{mg} / \mathrm{L}$ ), and $28 \%$ (422 to $303 \mathrm{mg} / \mathrm{L}$ ) at inner distances between electrodes of $1 \mathrm{~cm}, 2 \mathrm{~cm}, 3 \mathrm{~cm}$ and $4 \mathrm{~cm}$, respectively. On the other hand, at constant voltage value of $6 \mathrm{~V}$, the removal efficiency of COD was $48.7 \%, 27 \%, 23 \%$ and $22 \%$ at the different distances between electrodes. However, when the voltage decreased to $3 \mathrm{~V}$, the COD reduction increased to $56.5 \%$, $42 \%, 36 \%$ and $30 \%$ at the different distances between electrodes. It is obvious that variation in voltage value plays a central role in the process of treatment. The discussion of the influencing parameters will be discussed in the next section.

Using pH of 4 (Figure 3) and voltage value of 9V, the removal efficiency of COD was $45.4 \%$ (460 to $251 \mathrm{mg} / \mathrm{L}$ ), $30 \%$ (410 to $284 \mathrm{mg} / \mathrm{L}$ ), $24 \%$ (331 to $250 \mathrm{mg} / \mathrm{L}$ ), and $21 \%$ (323 to $254 \mathrm{mg} / \mathrm{L}$ ) at the different distances between electrodes. When the voltage value was decreased to $6 \mathrm{~V}$ and $3 \mathrm{~V}$, no significant removal of COD was observed where the maximum removal efficiency was $31.5 \%, 30 \%$, $29 \%, 21 \%$ and $37.6 \%, 34 \%, 28 \%$ and $25 \%$, respectively. When $\mathrm{pH}$ was increased to 6 (Figure 3), and using a voltage value of $9 \mathrm{~V}$, the percentage removal of COD was 85.5\% (460 to 66mg/L), 66\% (643 to $216 \mathrm{mg} / \mathrm{L}$ ), $62 \%$ (447 to $166 \mathrm{mg} / \mathrm{L}$ ), and $59 \%$ (440 to $178 \mathrm{mg} / \mathrm{L}$ ). However, when the voltage value was decreased to $6 \mathrm{~V}$ and $3 \mathrm{~V}$, the removal efficiency of COD was decreased to $67.9 \%, 65 \%, 57 \%, 49 \%$ and $60.5 \%, 58 \%, 53 \%, 51 \%$, respectively.

Further increase in $\mathrm{pH}$ to 8 (Figure 3) resulted in lower removal efficiency of COD of $22.7 \%$ (590 to $456 \mathrm{mg} / \mathrm{L}$ ), $21 \%$ (442 to $350 \mathrm{mg} / \mathrm{L}$ ), $18 \%$ (500 to $412 \mathrm{mg} / \mathrm{L}$ ) and $15 \%$ (480 to $410 \mathrm{mg} / \mathrm{L}$ ) at the different distances between electrodes. However, when the voltage decreased to $6 \mathrm{~V}$ and $3 \mathrm{~V}$, a small increase in the performance of COD was noted where the higher removal efficiency was $33.2 \%$, $31 \%, 27 \%, 23 \%$ and $34.08 \%, 31 \%, 28 \%, 27 \%$, respectively. Naje et al. [29] showed that the COD reduction at $\mathrm{pH} 4$ was $77 \%$, whereas in the present study the higher percentage of COD removal at $\mathrm{pH} 4$ was $45.4 \%$, which is slightly different from COD reduction from the previous study. The higher COD removal is most likely due to the larger surface area of flocs that will contribute to quick absorption trap by colloidal particles. In the current study, however, COD removal was lower with the acidic condition. This observation could be due to the types of organic compounds included in textile wastewater samples. From the previous results, it can be summarized that the optimum conditions which gave the maximum removal efficiency of COD were at a $\mathrm{pH}$ of $6,9 \mathrm{~V}$ of constant voltage, and $1 \mathrm{~cm}$ between electrodes. 


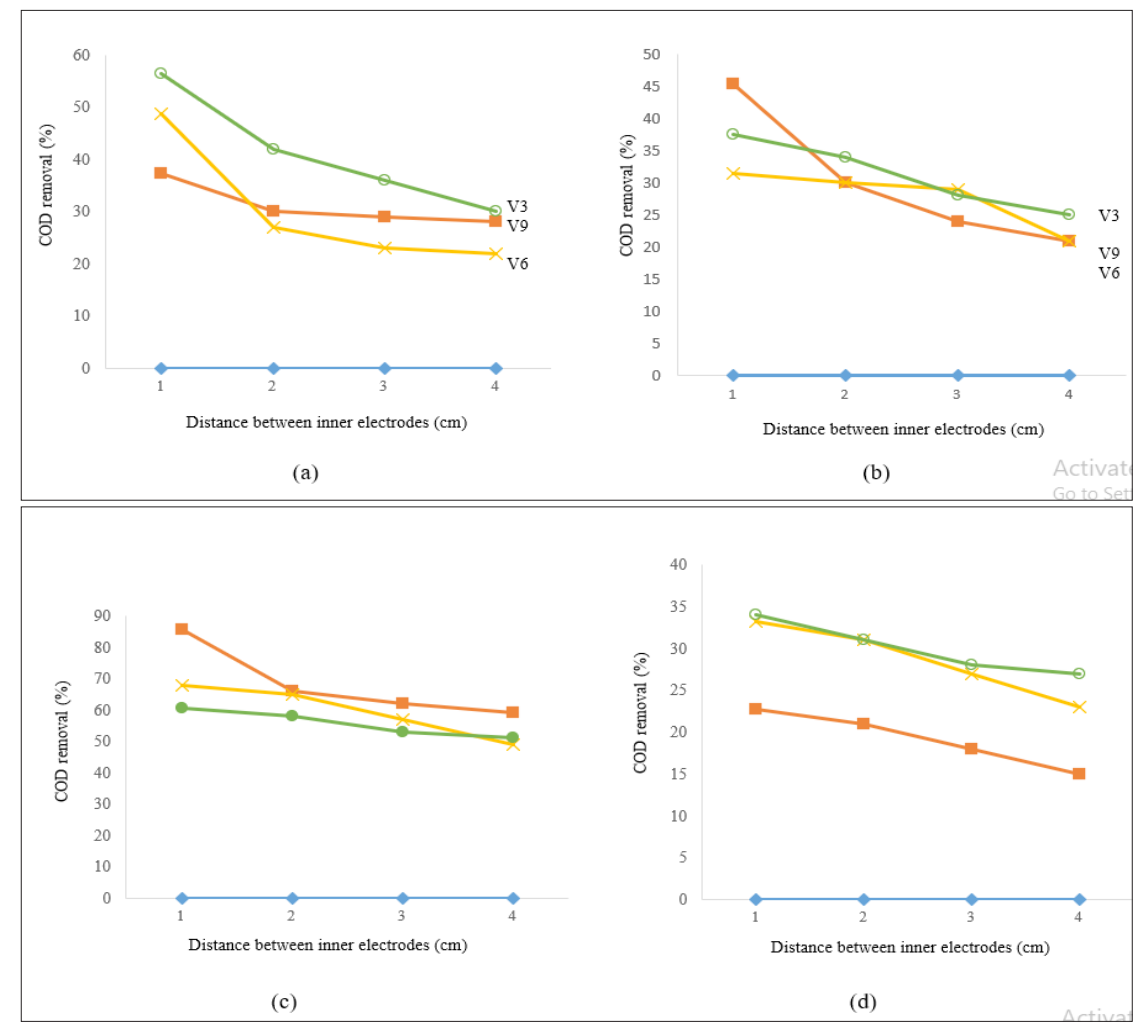

Figure 3: Removal efficiency of COD versus distance between inner electrodes at (a) raw $\mathrm{pH}$, (b) $\mathrm{pH}$, (c) $\mathrm{pH}$, and (d) $\mathrm{pH} 8$.

\section{Influence of removal efficiency by operating parameters}

The removal efficiency of COD, turbidity, and color was investigated under different conditions of $\mathrm{pH}$, voltage values, and distances between electrodes. The three parameters were considered as the influential factors that affect the removal performance. According to Amour et al. [32], the current density applied was the main operating variable for the coagulant production rate, oxygen evolution, heat generation and bubble production rate; thus, it controls the electrolysis process performance as well as operating costs. Voltage is also a significant variable which controls the pollutant removal reaction rate by determining the producing of bubble rate, bubble size and the formation of the floc, which can influence pollutant removal performance by the electro-coagulation process. The distance between electrodes is also an influential factor in the process of electrolysis. According to Azarian et al. [33] the electrodes distancing influences electrolysis energy consumption, particularly when the electrical conductivity of the samples tested is low. In the current study, four different distances have been tested, as mentioned earlier. The distance of $1 \mathrm{~cm}$ resulted in optimum removal, which was in agreement with Naje et al. [29]. By increasing the distance, the attraction of the dissolved solution between the electrodes and current ions would be reduced. As a result, the flocculation process will be slow and results in decreasing the efficiency of the treatment process. The interaction of colloidal particles or flocs can have a major impact on their settling and floating characteristics if the inter-electrode distance is small $(1 \mathrm{~cm})$, resulting in high particle collisions and high pollutant removal. Therefore, increasing the inter-electrode distance reduces pollutant removal and reduces the efficiency of the electrolysis process [34].

In addition to the parameters, $\mathrm{pH}$ plays a central role in the electrolysis process. According to Atashzaban et al. [35], pH influences the reductions of COD and TSS. The maximum reduction was achieved at both electrodes at a neutral $\mathrm{pH}$ of 6-7. Hydrogen bubbles were usually created at neutral $\mathrm{pH}$ at the cathode and can be applied to generate an area to link liquid, gas, and solid, and to collect the neutral and colloidal particles. In the current study, the highest removal of pollutant occurred at pH 6 (neutral) condition. During electro-coagulation, the metallic cations created to interact with $\mathrm{OH}$-to form hydroxides which adsorb pollutants (bridge coagulation). In some situations, the hydroxides form larger lattice-like structures that sweep through the water (sweeping coagulation). By neutralizing the colloidal particle charge, cations or hydroxyl ions can also form a pollutant precipitate. In addition, the adhesion of bubbles to flocs results in electro-flotation, which can also help in the removal of pollutants [36]. The interaction between the particles would also cause dense flocs to form. The dense flocs have a large surface area in which soluble organic compounds and colloidal particle trapping are quickly adsorbed, resulting in maximum COD, turbidity and color reduction through flotation and sedimentation. 


\section{Size of flocs at optimum conditions}

As illustrated earlier, the maximum reduction of the pollutant was obtained at $\mathrm{pH}$ of $6,9 \mathrm{~V}$ of constant voltage, and $1 \mathrm{~cm}$ between electrodes. The flocs size was investigated using these optimum conditions, as shown in Figure 4 below. It can be seen that the size of flocs formed at optimum condition was achieved at diameter $0.9(582.230 \mu \mathrm{m})$. At this diameter, the largest size of flocs was obtained, which cause high removal of pollutants. This observation is most likely due to the neutralization state, where the flocs start to form as particles collisions occurred. The higher collision efficiency will give a higher removal efficiency of pollutants [37]. When the distance between electrodes increased to $2 \mathrm{~cm}$, the flocs were found to be smaller in diameter 0.9 with a value of $495,662 \mu \mathrm{m}$, as shown in Figure 5. Further increase in the distance between electrodes resulted in smaller flocs size at diameter 0.9 with a value of $252.560 \mu \mathrm{m}$ and $148.392 \mu \mathrm{m}$ for a distance between electrodes of $3 \mathrm{~cm}$ and $4 \mathrm{~cm}$, respectively. From the previous results, it was obvious that the distance between electrodes was an influential factor that affects the size of the flocs. It is believed that the distance between electrodes impacts electrolysis energy consumption, particularly when samples have low electrical conductivity. Increasing the distance between electrodes will reduce the attraction in a dissolved solution between the electrodes and the ions present. Therefore, the size of the flocs will be reduced and hence, the flocculation process will be slow and results. At a closer inter-electrode distance $(1 \mathrm{~cm})$, colloidal particles or flocs may interact significantly with their settling and flotation characteristics, resulting in high particle collisions, resulting in higher flocs size [34].

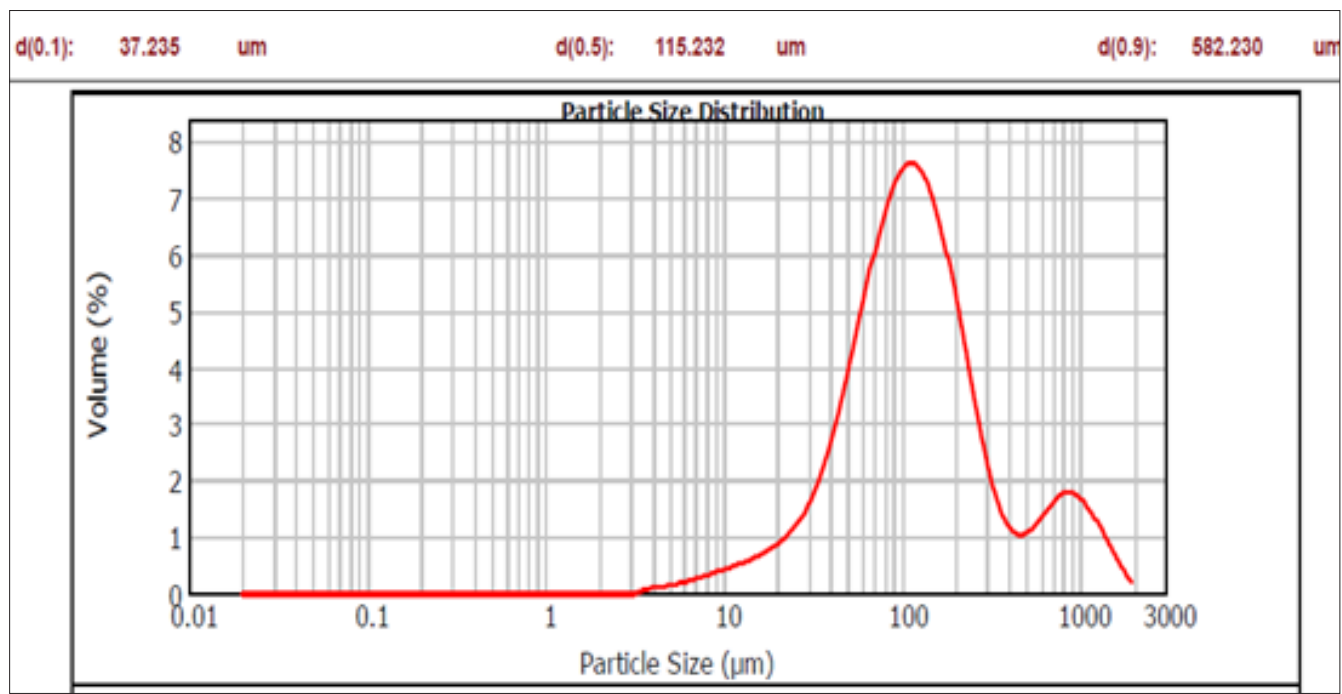

Figure 4: Particle size distribution for flocs at 9V, $1 \mathrm{~cm}$ between electrodes, and pH6.

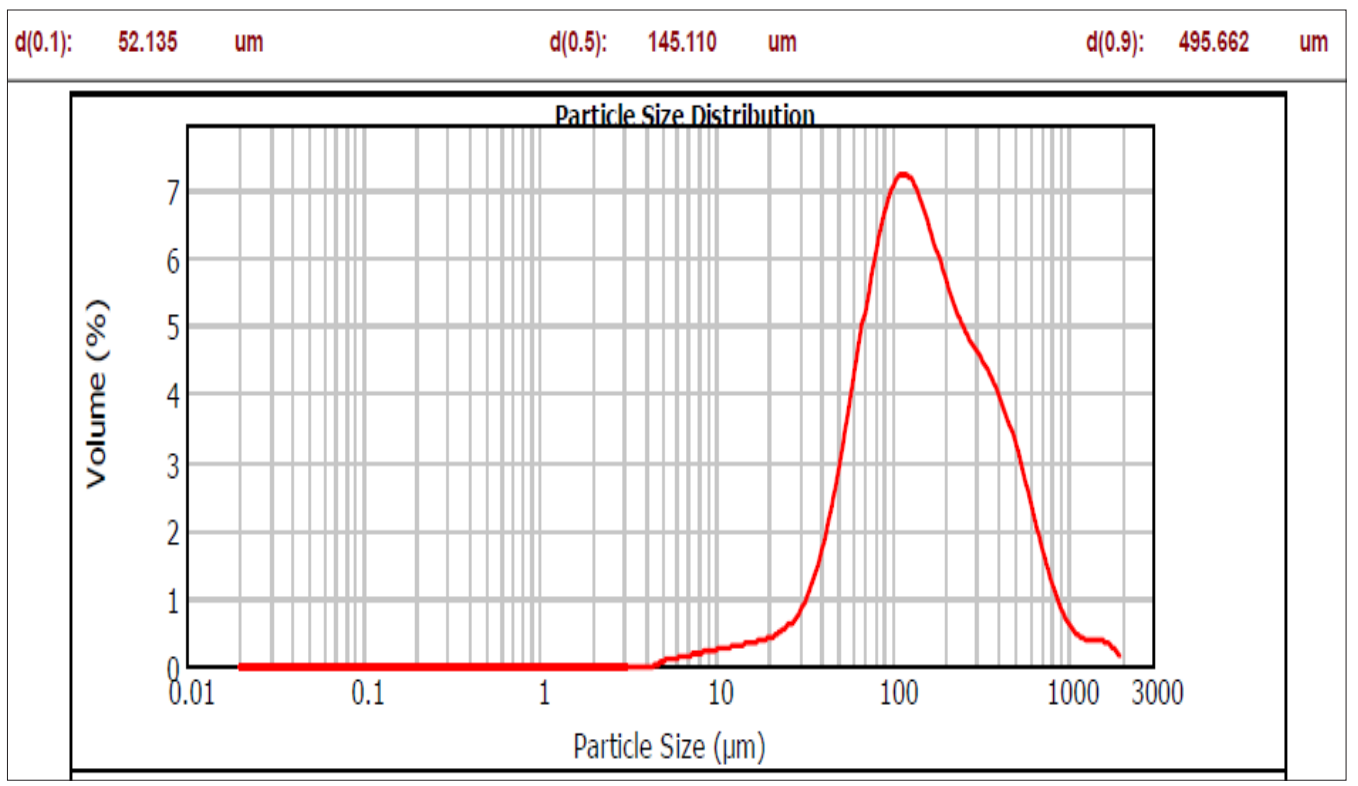

Figure 5: Particle size distribution for flocs at $9 \mathrm{~V}, 2 \mathrm{~cm}$ between electrodes, and pH6. 


\section{Conclusion}

In this study, the removal of COD, turbidity, and color from textile wastewater (from the last process of dyeing and finishing) was investigated using the electrolysis process by employing carbon bars as electrodes. Carbon electrodes is found to be an effective coagulant as it generate coagulants in the textile wastewater through the electrodes. Usage of carbon electrode is found to be safe as its not giving detrimental impact towards human health by metal precipitation along the pollutant removal. Electrolysis process was examined under different conditions. It was found that the voltage value affects the rate of reaction of pollutant removal and can affect the removal where the higher voltage value resulted in higher removal efficiency. Also, the distance between electrodes and $\mathrm{pH}$ significantly affects the removal efficiency, where the less distance between electrodes resulted in higher removal efficiency and $\mathrm{pH}$ plays a central role in the treatment process, where the higher removal efficiency was achieved at neutral pH respectively. Under optimum conditions ( $\mathrm{pH}$ : 6, constant voltage: 9V, inter-electrode distance: $1 \mathrm{~cm}$ ), $85.5 \%$ of COD removal, $89.2 \%$ of turbidity removal and $85.2 \%$ of color removal were obtained. The flocs size was found to be bigger in the case of less distance between electrodes with $1 \mathrm{~cm}$ inter-electrode distance give $582.230 \mu \mathrm{m}$ flocs diameter size. The study demonstrated that the electrolysis process was efficient and relatively rapid and could be used as an alternative treatment for textile effluent in removing COD, turbidity and color from textile wastewater. At present, there is little pollutant removal efficiency in textile wastewater by using carbon electrodes electrolysis was determined. This leaves room for more experimental work to be conducted in order to establish more data in term of other pollutant removal such as suspended solids, heavy metal and phosphate removal to enhance better water quality after electrolysis process.

\section{Acknowledgement}

This work was funded by Ministry of Higher Education Malaysia under Fundamental Research Scheme (FRGS) (Grant No. 203/PAWAM/6071415) for research associated with the Solid Waste Management Cluster, Engineering Campus, Universiti Sains Malaysia.

\section{References}

1. Ballaa W, Essadki AH, Gourich B, Dassaa A, Chenik H, et al. (2010) Electrocoagulation/electro-flotation of reactive, disperse and mixture dyes in an external-loop airlift reactor. J Hazard Mater 184(1-3): 710716.

2. El-Ashtoukhy ESZ, Amin NK (2010) Removal of acid green dye 50 from wastewater by anodic oxidation and electrocoagulation-A comparative study. J Hazard Mater 79(1-3): 113-119.

3. Ali H (2010) Biodegradation of synthetic dyes-A review. Water Air Soil Pollut 213: 251-273.

4. Khattab TA, Abdelrahman MS, Rehan M (2020) Textile dyeing industry: environmental impacts and remediation. Environ Sci Pollut Res Int27(4): 3803-3818.

5. Katheresan V, Kansedo J, Yon Lau S (2018) Efficiency of various recent wastewater dye removal methods: A review. J Environ Chem Eng 6(4):
4676-4697.

6. Bakar NA, Othman N, Yunus ZM, Daud Z, Norisman NS, et al. (2020) Physico-Chemical Water Quality Parameters Analysis on Textile. IOP Conference Series: Earth and Environmental Science 498(1): 012077.

7. Tian Q Ran M, Fang G, Ding L, Pan A, et al. (2020) $\mathrm{ZnAl}_{2} \mathrm{O}_{4} / \mathrm{BiPO}_{4}$ composites as a heterogeneous catalyst for photo-Fenton treatment of textile and pulping wastewater. Separation and Purification Technology 239: 116574.

8. Bilińska L, Blus, K, Gmurek M, Ledakowicz S (2019) Coupling of electrocoagulation and ozone treatment for textile wastewater reuse. Chemical Engineering Journal 358: 992-1001.

9. Jegatheesan V, Pramanik BK, Chen J, Navaratna D, Chang CY, et al. (2016) Treatment of textile wastewater with membrane bioreactor: a critical review. Bioresource Technology 204: 202-212.

10. Naumczyk,J, Szpyrkowicz L, Zilio Grandi F (1996) Electrochemical treatment of textile wastewater. Water Science and Technology 34(11): $17-24$.

11. Lin SH, Peng CF (1994) Treatment of textile wastewater by electrochemical method. Water Research 28(2): 277-282.

12. Paździor K, Bilińska L, Ledakowicz S (2019) A review of the existing and emerging technologies in the combination of AOPs and biological processes in industrial textile wastewater treatment. Chemical Engineering Journal 376: 120597.

13. Cinperi NC, Ozturk E, Yigit NO, Kitis M (2019) Treatment of woolen textile wastewater using membrane bioreactor, nanofiltration and reverse osmosis for reuse in production processes. Journal of Cleaner Production 223: 837-848.

14. Bechtold T, Mahmud-Ali A, Ganglberger E, Geissler S (2008) Efficient processing of raw material defines the ecological position of natural dyes in textile production. International Journal of Environment and Waste Management 2(3): 215-232.

15. Aquino JM, Rocha Filho RC, Bocchi N, Biaggio SR (2013) Electrochemical degradation of the Disperse Orange 29 dye on a $\beta-\mathrm{PbO}_{2}$ anode assessed by the response surface methodology. J Environ Chem Eng 1(4): 954961.

16. Palácio SM, Espinoza Quiñones FR, Módenes AN, Oliveira CC, Borba FH, et al. (2009) Toxicity assessment from electro-coagulation treatedtextile dye wastewaters by bioassays. J Hazard Mater 172(1): 330-337.

17. Cao JS, Lin JX, Fang F, Zhang MT, Hu ZR (2014) A new absorbent by modifying walnut shell for the removal of anionic dye: Kinetic and thermodynamic studies. Bioresour Technol 163: 199-205.

18. Palácio SM, Espinoza Quiñones FR, Módenes AN, Manenti DR, Oliveira CC, et al. (2012) Optimized photocatalytic degradation of a mixture of azo dyes using a $\mathrm{TiO}_{2} / \mathrm{H}_{2} \mathrm{O}_{2} / \mathrm{UV}$ process. Water Sci Technol 65(8): 13921398.

19. Zhao L, Zhang S, Uluko H, Liu L, Lu J, et al. (2014) Effect of ultrasound pretreatment on rennet-induced coagulation properties of goat's milk. Food Chemistry 165: 167-174.

20. Bazrafshan E, Mahvi AH (2014) Textile wastewater treatment by electrocoagulation process using aluminum electrodes. Iranian Journal of Health Sciences 2(1): 16-29.

21. Chopra AK, Sharma AK, Kumar V (2011) Overview of electrolytic treatment: An alternative technology for purification of wastewater. Archives of Applied Science Research 3: 191-206.

22. APHA (2005) WEF (American public health association, American water works association and Water environment federation). Standard Methods for the Examination of Water and Wastewater. 
23. Abdullah TA, Salman A, Juzsakova T, Al-Asadi M, Domokos E, et al. (2018) Treatment of oily wastewater using electro-coagulation method with iron poles pers center. In their articles presented, in oral or poster sessions, during the GLOREP 2018 conference, organized in Timisoara, Romania, by $15-17^{\text {th }}$ November 2018 , under the auspices of the Balkan Environmental, p. 5.

24. Uwidia IE and Ejeomo C (2014) Characterization of textile wastewater discharges in Nigeria and its pollution implications. Global Journal of Research in Engineering.

25. Helmy Q, Notodarmojo S, Aruan IA, Apriliawati R (2017) Removal of color and chemical oxygen demand from textile wastewater using advanced oxidation process (AOPs). IPTEK Journal of Proceedings Series 3: 474-481.

26. MQA (2009) Environmental quality act 1974, Industrial effluent regulations.

27. Manikandan S, Saraswathi R, Ansari AMS (2018) Effect of pH and electrolysis time on removal of reactive black B dye by electrochemical treatment. Asian Journal of Engineering and Applied Technology 7: 4547.

28. Holt PK, Barton GW, Wark M, Mitchell CA (2002) A quantitative comparison between chemical dosing and electrocoagulation. Collision Surface Part A: Physicochemical Engineering 211(2-3): 233-248.

29. Naje AS, Chelliapan S, Zakaria Z, Abbas SA (2015) Treatment performance of textile wastewater using electro-coagulation (EC) process under combined electrical connection of electrodes. Int J Electrochem Sci 10: 5924-5941.
30. Chen G (2004) Electrochemical technologies in wastewater treatment Separation and Purification Technology 38(1): 11-41.

31.Zarei A, Biglari H, Mobini M, Dargahi A, Ebrahimzadeh G, et al. (2018) Disinfecting poultry slaughterhouse wastewater using copper electrodes in the electro-coagulation process. Polish Journal of Environmental Studies 27(4): 1907-1912.

32. Amour A, Merzouk B, Leclerc JP, Lapicque F (2016) Removal of reactive textile dye from aqueous solutions by electro-coagulation in a continuous cell. Desalination and Water Treatment 57(48-49): 22764-22773.

33. Azarian G, Rahmani AR, Atashzaban Z, Nematollahi D (2018) New batch electro-coagulation process for treatment and recovery of high organic load and low volume egg processing industry wastewater. Process Safety and Environmental Protection 119: 96-103.

34. Sridhara R, Sivakumar V, Immanuel V, Maran JP (2011) Treatment of pulp and paper industry bleaching effluent by electro-coagulant process. Journal of Hazardous Material 186(2-3): 1495-1502.

35. Atashzaban Z, Seidmohammadi A, Nematollahi D, Azarian G, Shayesteh $\mathrm{OH}$, et al. (2016) The efficiency of electrocoagulation and electroflotation processes for removal of polyvinyl acetate from synthetic effluent. Avicenna Journal of Environmental Health Engineering 3: 7469-7469.

36. Holt PK, Barton WL, Mitchell CA (2005) The future for electrocoagulation as localized water treatment technology. Chemosphere 59(3): 355-367.

37. Yukselen MA, Gregory J (2004) The reversibility of floc breakage. International Journal of Mineral Processing 73(2-4): 251-259. 